\title{
Stress ulcer prophylaxis with proton pump inhibitors or histamine 2 receptor antagonists in critically ill adults - a meta- analysis of randomized controlled trials with trial sequential analysis
}

Xiaoyang Zhou ${ }^{1}$, Hanyuan Fang ${ }^{2}$, Jianfei Xu${ }^{1}$, Peifu Chen ${ }^{1}$, Xujun $\mathrm{Hu}^{1}$, Bixin Chen ${ }^{1}$, Hua Wang ${ }^{1}$, Caibao Hu ${ }^{3^{*}}$ and Zhaojun $\mathrm{Xu}^{1 *}$

\begin{abstract}
Background: Proton pump inhibitors (PPI) and histamine 2 receptor antagonists (H2RA) have been widely used as stress ulcer prophylaxis (SUP) in critically ill patients, however, its efficacy and safety remain unclear. This study aimed to assess the effect of SUP on clinical outcomes in critically ill adults.

Methods: Literature search was conducted in PubMed, EMBASE, Web of Science, and the Cochrane database of clinical trials for randomized controlled trials (RCTs) that investigated SUP, with PPI or H2RA, versus placebo or no prophylaxis in critically ill patients from database inception through 1 June 2019. Study selection, data extraction and quality assessment were performed in duplicate. The primary outcomes were clinically important gastrointestinal (Gl) bleeding and overt Gl bleeding. Conventional meta-analysis with random-effects model and trial sequential analysis (TSA) were performed.

Results: Twenty-nine RCTs were identified, of which four RCTs were judged as low risk of bias. Overall, SUP could reduce the incident of clinically important Gl bleeding [relative risk (RR) $=0.58$; $95 \%$ confidence intervals (Cl): $0.42-$ 0.81 ] and overt Gl bleeding ( $R R=0.48 ; 95 \% \mathrm{Cl}: 0.36-0.63)$, these results were confirmed by the sub-analysis of trials with low risk of bias, TSA indicated a firm evidence on its beneficial effects on the overt Gl bleeding (TSA-adjusted Cl: 0.31-0.75), but lack of sufficient evidence on the clinically important GI bleeding (TSA-adjusted Cl: 0.23-1.51). Among patients who received enteral nutrition (EN), SUP was associated with a decreased risk of clinically important Gl bleeding (RR $=0.61 ; 95 \% \mathrm{Cl}$ : 0.44-0.85; TSA-adjusted Cl: $0.16-2.38$ ) and overt Gl bleeding (RR =0.64; 95\% Cl: 0.42-0.96; TSA-adjusted Cl: 0.12-3.35), but these benefits disappeared after adjustment with TSA. Among patients who did not receive EN, SUP had only benefits in reducing the risk of overt Gl bleeding (RR $=0.37 ; 95 \% \mathrm{Cl}$ : 0.25-0.55; TSA-adjusted Cl: 0.22-0.63), but not the clinically important Gl bleeding (RR $=0.27$; $95 \%$ Cl: $0.04-2.09$ ).
\end{abstract}

Conclusions: SUP has benefits on the overt Gl bleeding in critically ill patients who did not receive EN, however, its benefits on clinically important Gl bleeding still needs more evidence to confirm.

Keywords: Stress ulcer, Proton pump inhibitors, Histamine 2 receptor antagonists, Critically ill, Gastrointestinal bleeding

\footnotetext{
*Correspondence: zjicu1996@163.com; nbey_icu@163.com

3 Department of Intensive Care Medicine, Zhejiang Hospital, Hangzhou

310000, Zhejiang, China

${ }^{1}$ Department of Intensive Care Medicine, HwaMei Hospital, University Of

Chinese Academy of Sciences, Ningbo 315000, Zhejiang, China

Full list of author information is available at the end of the article
}

(c) The Author(s). 2019 Open Access This article is distributed under the terms of the Creative Commons Attribution 4.0 International License (http://creativecommons.org/licenses/by/4.0/), which permits unrestricted use, distribution, and

reproduction in any medium, provided you give appropriate credit to the original author(s) and the source, provide a link to the Creative Commons license, and indicate if changes were made. The Creative Commons Public Domain Dedication waiver (http://creativecommons.org/publicdomain/zero/1.0/) applies to the data made available in this article, unless otherwise stated. 


\section{Background}

Critically ill patients admitted to the intensive care unit (ICU) are often exposed to the potential risk factors for stress-related gastrointestinal (GI) bleeding, which includes mechanical ventilation, coagulopathy, renal replacement therapy, etc. $[1,2]$. Thus, critically ill patients are always at high risk of stress-related GI bleeding. However, the incidence of stress-related GI bleeding in ICU patients has decreased notably to approximately 2$5 \%[2,3]$ over the past decade, which is due, at least in part, to improved hemodynamic management and better control of mechanical ventilation (MV) [4]. Although, critically ill patients complicated with GI bleeding are still associated with higher mortality and worse clinical outcomes $[5,6]$, a multi-center cohort study recorded a 90-day mortality of more than $50 \%$ in ICU patients complicated with clinically important GI bleeding [2]. Hence, it is important and necessary for ICU patients to take pharmacy prophylaxis for stress-related GI bleeding.

Proton pump inhibitors (PPI) and histamine2 receptor antagonists (H2RA) have been used as stress ulcer prophylaxis (SUP) in critically ill patients for more than 40 years [7], however, its efficacy and safety remain controversial. Over the past decades, numerous randomized controlled trials (RCTs) [7-13] were conducted to investigate the relationship of SUP and clinical outcomes in critically ill patients, several meta-analyses [14-16] found that SUP with PPI or H2RA was effective in preventing GI bleeding compared with placebo or no prophylaxis, however, a recent meta-analysis by Huang et al. [17] concluded that SUP with PPI or H2RA had no beneficial effects on GI bleeding in ICU patients receiving enteral nutrition (EN). Meanwhile, some studies [14, 17] revealed an increased risk of pneumonia with use of PPI or H2RA, but others studies [15, 16] suggested that SUP with PPI or H2RA was not accompanied by increased incident of pneumonia. We are confused about the benefits and harms of SUP with PPI or H2RA in critically ill patients in consideration of the above contradictory results. Recently, several RCTs, the SUP-ICU trial [18] in particular, were published, these studies will expand the sample size and may make a firm conclusion on the efficacy and safety of SUP in critically ill patients. For that reason, we conducted a new meta-analysis of RCTs with trial sequential analysis to detect the effect of SUP, with PPI or H2RA, on clinical outcomes in critically ill patients. Also, the difference of the outcome effects between patients who received EN and those did not receive EN will be investigated.

\section{Methods}

\section{Search strategy}

This meta-analysis was performed in accordance with the PRISMA guidance [19]. Literature search with medical subject heading terms and liberal terms was performed by two independent authors (Zhou X and Fang H) for RCTs of adult critically ill patients, where SUP with PPI or H2RA was compared to placebo or no prophylaxis, in PubMed, EMBASE, Web of Science and the Cochrane database of clinical trials from database inception through 5 November 2018, the last database search was updated on 1 June 2019. We also reviewed articles from others meta-analyses to avoid missing relevant literature. There was no restriction on language in this meta-analysis. The detailed search strategy is shown in the Additional file 1.

\section{Study selection}

Firstly, all searched records were filtered to exclude duplicates. Then, three authors (Xu J, Chen $\mathrm{P}$, and $\mathrm{Hu} \mathrm{X}$ ) independently screened the titles and abstracts of the remaining records to determine whether the studies met the inclusion criteria. The eligible articles were included in a further review of the full-text in accordance with the inclusion and exclusion criteria. The inclusion criteria in our meta-analysis include: 1) prospective RCTs where the interventions group received SUP with PPI or H2RA, with no restrictions on dosage, duration of drug used, or drug-delivery methods, and the control group received placebo or no prophylaxis; 2) adults critically ill patients (age $\geq 18$ years) admitted to the ICU. The primary outcomes were clinically important GI bleeding and overt GI bleeding, the secondary outcomes includes all-cause mortality, incident of pneumonia and Clostridium difficile infection (CDI), and the tertiary outcomes were duration of MV and ICU stay. Studies that reported at least one of the above outcomes were included in this meta-analysis. However, studies that enrolled critically ill patients who were not admitted to the ICU were excluded. The different opinions between the three authors were discussed to reach a consensus.

\section{Data extraction}

The associated data were extracted independently by two reviewers (Chen $\mathrm{B}$ and Wang $\mathrm{H}$ ) using a standardized data extraction protocol, including characteristics of the included studies, details of the population enrolled, detailed information on the interventions including the type of SUP, dose, and regimen. The interested clinical outcomes were also recorded. In studies in which various mortalities were reported, the longest follow-up allcause mortality was included in analysis. We predefined overt GI bleeding as evidence of hematemesis, melena, hematochezia, or coffee-grounds emesis or aspirate regardless of other clinical findings, clinically important GI bleeding was defined as evidence of GI bleeding plus any of the following signs: significant hemodynamic changes not explained by other causes, need for transfusion of 
blood, significant decrease in hemoglobin level, or need for surgery to control the bleeding [14]. Discrepancies between reviewers were resolved through discussion.

\section{Quality assessment}

The risk of bias of each included studies were assessed by two independent authors ( $\mathrm{Hu} \mathrm{C}$ and $\mathrm{Xu} \mathrm{Z}$ ) for the primary outcomes (clinically important GI bleeding and overt GI bleeding) in the following six domains: adequate sequence generation, allocation concealment, blinding of participants and personnel, blinding of outcome assessment, incomplete outcome data, selective reporting, and other bias [20,21]. Only studies that exhibited a low risk of bias in all domains were judged as low risk of bias. We resolved the disagreements by discussing with a third reviewer until a consensus.

\section{Statistical analysis}

Data analyses were conducted using Stata/SE 11.0 (StataCorp, College Station, TX, USA). We calculated relative risk (RR) for dichotomous data and mean differences (MD) for continuous data, with 95\% corresponding confidence interval (CI). In studies with multiple intervention groups received different type of SUP (such as one group received PPI, and another group received H2RA), the number of events and total subjects in the control group would be divided approximately evenly into multiple groups to make multiple comparisons, the means and SD were left unchanged, if the intervention groups received same type of SUP, the multiple groups would be combined into a single group, and the means and SD can be combined using methods described in Cochrane handbook (Chapter 7) [20].

Statistical heterogeneity among trials was evaluated by inspecting the Forest plots and quantified using the diversity $\left(\mathrm{D}^{2}\right)$ and inconsistency factor $\left(\mathrm{I}^{2}\right)$ statistics. Both fixed-effects and random-effects model were used to calculate the pooled results for all outcomes (Table 1). Given the potential clinical and statistical heterogeneity (in the type of SUP, drug-delivery methods, and ICU setting, etc.) between included trials, we reported the random-effects pooled data as the main results [22]. Subgroup analyses were also conducted for all outcomes based on the overall risk of bias of included studies (low or high risk of bias), the type of SUP (PPI or H2RA), and whether EN was received (yes or no). Funnel plots combined with Begg's and Egger's tests were performed to assess publication bias for the primary outcomes if the number of included trials was more than 10. Considering that the primary and secondary outcomes were multiple, we assessed the primary outcomes with statistical significance set at a $P$ value of 0.033 or less, the secondary outcomes at a $P$ value of 0.025 or less, and the tertiary outcomes at a $P$ value of 0.33 or less [22].

\section{Trial sequential analysis}

Because of the increased risk of random errors resulted from sparsity data and repeated significance testing [23], we conducted trial sequential analysis (TSA) for the primary and secondary outcomes to assess this risk using TSA program version 0.9.5.10 beta (available from www. ctu.dk/tsa). We calculated the TSA-adjusted CI using fixed-effects and random-effects models for heterogeneity $\left[D^{2}\right.$ adjustment $]$, and the random-effects result was reported as the main result (Table 1). Because the overall risk of falsely rejecting the null hypothesis (the type I error) will increase when performing multiple hypothesis tests [22], we calculated the TSA-adjusted 95\% CI with a type I error of $5 \%$ with a statistical signifcance level of $3.3 \%$ for the co-primary outcomes and $2.5 \%$ for the cosecondary outcomes, a beta (power) of $80 \%$, and a $\mathrm{D}^{2}$ suggested by the included trials. If the actual measured $\mathrm{D}^{2}$ was zero, a $\mathrm{D}^{2}$ of $25 \%$ was used because the heterogeneity may be expected to increase when further studies are included [22]. The required information size was calculated based on a relative risk reduction of $20 \%$ in the risk of clinically important GI bleeding and overt GI bleeding in the control group calculated from the conventional meta-analysis [21].

\section{Results \\ Study selection}

The PRISMA flowchart of this study is shown in Fig. 1 and the reasons for exclusion of illegible studies are presented in (Additional file 1: Table S1). We searched a total of 10,562 records in the abovementioned database, additional 119 records from other meta-analyses were also identified. Among these records, 946 duplicate records and 9630 records, which were ineligible for our inclusion criteria, were excluded after screening the title and abstract. Then, the remaining 105 studies were included in the review of the full text. Finally, a total of 29 studies [7-13, 18, 24-44] met the eligibility criteria and were included in this meta-analysis.

\section{Characteristics of included studies}

The detailed characteristics and clinical outcomes of the individual studies are described in (see Additional file 1: Table S2 and Additional file 1: Table S3). Among these included RCTs [7-13, 18, 24-44], six trials $[18,24,30,36,38,43]$ were published in recent 3 years, seven trials $[11-13,18,24,30,44]$ were multi-center, and twenty-two trials $[7-10,25-$ $29,31-43]$ were single-center. The discrepancy in the number of subjects between trials were large and it varied from 25 to 3298. The subjects were from medical ICU [7, $25,26,30,31,38,40]$, surgical ICU $[8,10,13,28,34,35$, $37,39,41,44]$, or both $[9,11,12,18,24,27,29,32,33,36$, $42,43]$. SUP with H2RA was reported in 20 trials [7-13, 
Table 1 The conventional meta-analysis and trial sequential analysis using random-effects and fixed-effects for all outcomes

\begin{tabular}{|c|c|c|c|c|c|c|c|c|c|c|}
\hline & \multicolumn{4}{|c|}{ Conventional meta-analysis } & \multicolumn{6}{|c|}{ Trial sequential analysis (TSA) } \\
\hline & \multicolumn{2}{|c|}{ Random-effects } & \multicolumn{2}{|l|}{ Fixed-effects } & \multirow[b]{2}{*}{$1^{2}$} & \multirow[b]{2}{*}{$\begin{array}{l}\text { Random-effect } \\
\text { TSA-adjusted } \\
95 \% \mathrm{Cl}\end{array}$} & \multirow[b]{2}{*}{$\begin{array}{l}\text { Fixed-effect } \\
\text { TSA-adjusted } \\
95 \% \mathrm{Cl}\end{array}$} & \multirow[b]{2}{*}{$\begin{array}{l}\text { Actual } \\
\text { diversity } \\
\left(D^{2}\right)\end{array}$} & \multirow{2}{*}{$\begin{array}{l}\text { Incidence } \\
\text { in control } \\
\text { group }\end{array}$} & \multirow{2}{*}{$\begin{array}{l}\text { Required } \\
\text { informatio } \\
\text { size }\end{array}$} \\
\hline & $\begin{array}{l}\text { RR or } \\
\text { WMD } \\
(95 \% \text { Cl) }\end{array}$ & $P$ & $\begin{array}{l}\text { RR or } \\
\text { WMD } \\
(95 \% \mathrm{Cl})\end{array}$ & $P$ & & & & & & \\
\hline \multicolumn{11}{|l|}{ Primary endpoints } \\
\hline \multicolumn{11}{|l|}{ Clinically important Gl bleeding } \\
\hline All trials (11 trials) & $\begin{array}{l}0.58 \\
(0.42-0.81)\end{array}$ & 0.001 & $\begin{array}{l}0.56 \\
(0.41-0.76)\end{array}$ & $\begin{array}{l}< \\
0.001\end{array}$ & $0 \%$ & $0.23-1.51$ & $0.22-1.39$ & $0 \%$ & $4.6 \%$ & 22,114 \\
\hline Low risk of bias (4 trials) & $\begin{array}{l}0.64 \\
(0.45-0.92)\end{array}$ & 0.017 & $\begin{array}{l}0.64 \\
(0.45-0.92)\end{array}$ & 0.016 & $0 \%$ & $0.15-2.80$ & $0.15-2.77$ & $0 \%$ & $4.1 \%$ & 24,928 \\
\hline High risk of bias (7 trials) & $\begin{array}{l}0.38 \\
(0.17-0.84)\end{array}$ & 0.017 & $\begin{array}{l}0.35 \\
(0.18-0.67)\end{array}$ & 0.002 & $11.8 \%$ & $0.01-9.93$ & $0.03-4.93$ & $19 \%$ & $6.7 \%$ & 13,827 \\
\hline Received PPI (6 trials) & $\begin{array}{l}0.61 \\
(0.43-0.88)\end{array}$ & 0.008 & $\begin{array}{l}0.61 \\
(0.43-0.88)\end{array}$ & 0.008 & $0 \%$ & $0.14-2.70$ & $0.14-2.68$ & $0 \%$ & $3.8 \%$ & 26,970 \\
\hline Received H2RA (6 trials) & $\begin{array}{l}0.45 \\
(0.17-1.22)\end{array}$ & 0.116 & $\begin{array}{l}0.42 \\
(0.23-0.78)\end{array}$ & 0.006 & $42.6 \%$ & - & - & $50 \%$ & $10.4 \%$ & - \\
\hline Received EN (8 trials) & $\begin{array}{l}0.61 \\
(0.44-0.85)\end{array}$ & 0.004 & $\begin{array}{l}0.61 \\
(0.44-0.84)\end{array}$ & 0.003 & $0 \%$ & $0.16-2.38$ & $0.16-2.33$ & $0 \%$ & $4.2 \%$ & 24,310 \\
\hline $\begin{array}{l}\text { Did not receive EN ( } 3 \\
\text { trials) }\end{array}$ & $\begin{array}{l}0.27 \\
(0.04-2.09)\end{array}$ & 0.211 & $\begin{array}{l}0.27 \\
(0.10-0.73)\end{array}$ & 0.010 & $62.3 \%$ & - & - & $65 \%$ & $13.0 \%$ & - \\
\hline \multicolumn{11}{|l|}{ Overt Gl bleeding } \\
\hline All trials (27 trials) & $\begin{array}{l}0.48 \\
(0.36-0.63)\end{array}$ & $\begin{array}{l}< \\
0.001\end{array}$ & $\begin{array}{l}0.50 \\
(0.42-0.59)\end{array}$ & $\begin{array}{l}< \\
0.001\end{array}$ & $34.6 \%$ & $0.31-0.75$ & $0.38-0.65$ & $62 \%$ & $12.1 \%$ & 15,468 \\
\hline Low risk of bias (4 trials) & $\begin{array}{l}0.62 \\
(0.48-0.79)\end{array}$ & $\begin{array}{l}< \\
0.001\end{array}$ & $\begin{array}{l}0.62 \\
(0.49-0.79)\end{array}$ & $\begin{array}{l}< \\
0.001\end{array}$ & $0 \%$ & $0.37-1.04$ & $0.37-1.04$ & $0 \%$ & $8.6 \%$ & 11,384 \\
\hline High risk of bias (23 trials) & $\begin{array}{l}0.42 \\
(0.30-0.60)\end{array}$ & $\begin{array}{l}< \\
0.001\end{array}$ & $\begin{array}{l}0.40 \\
(0.32-0.51)\end{array}$ & $\begin{array}{l}< \\
0.001\end{array}$ & $37.4 \%$ & $0.25-0.72$ & $0.28-0.57$ & $52 \%$ & $18.1 \%$ & 7595 \\
\hline Received PPI (8 trials) & $\begin{array}{l}0.57 \\
(0.45-0.71)\end{array}$ & $\begin{array}{l}< \\
0.001\end{array}$ & $\begin{array}{l}0.57 \\
(0.45-0.71)\end{array}$ & $\begin{array}{l}< \\
0.001\end{array}$ & $0 \%$ & $0.36-0.88$ & $0.36-0.88$ & $0 \%$ & $8.9 \%$ & 10,969 \\
\hline Received H2RA (22 trials) & $\begin{array}{l}0.45 \\
(0.30-0.67)\end{array}$ & $\begin{array}{l}< \\
0.001\end{array}$ & $\begin{array}{l}0.43 \\
(0.33-0.54)\end{array}$ & $\begin{array}{l}< \\
0.001\end{array}$ & $45.7 \%$ & $0.26-0.79$ & $0.30-0.60$ & $59 \%$ & $19.3 \%$ & 8258 \\
\hline Received EN (13 trials) & $\begin{array}{l}0.64 \\
(0.42-0.96)\end{array}$ & 0.029 & $\begin{array}{l}0.60 \\
(0.48-0.74)\end{array}$ & $\begin{array}{l}< \\
0.001\end{array}$ & $25.7 \%$ & $0.12-3.35$ & $0.25-1.42$ & $71 \%$ & $9.2 \%$ & 27,681 \\
\hline $\begin{array}{l}\text { Did not receive EN (14 } \\
\text { trials) }\end{array}$ & $\begin{array}{l}0.37 \\
(0.25-0.55)\end{array}$ & $\begin{array}{l}< \\
0.001\end{array}$ & $\begin{array}{l}0.36 \\
(0.27-0.48)\end{array}$ & $\begin{array}{l}< \\
0.001\end{array}$ & $38.4 \%$ & $0.22-0.63$ & $0.25-0.52$ & $52 \%$ & $21.9 \%$ & 6029 \\
\hline \multicolumn{11}{|l|}{ Secondary endpoints } \\
\hline \multicolumn{11}{|l|}{ All-cause mortality } \\
\hline All trials (24 trials) & $\begin{array}{l}1.01 \\
(0.93-1.09)\end{array}$ & 0.842 & $\begin{array}{l}1.02 \\
(0.93-1.11)\end{array}$ & 0.692 & $0 \%$ & $0.90-1.13$ & $0.91-1.14$ & $0 \%$ & $26.8 \%$ & 3230 \\
\hline Low risk of bias (4 trials) & $\begin{array}{l}1.01 \\
(0.92-1.12)\end{array}$ & 0.813 & $\begin{array}{l}1.01 \\
(0.91-1.12)\end{array}$ & 0.858 & $0 \%$ & $0.67-1.52$ & $0.67-1.52$ & $0 \%$ & $29.8 \%$ & 2801 \\
\hline High risk of bias (20 trials) & $\begin{array}{l}1.00 \\
(0.87-1.16)\end{array}$ & 0.994 & $\begin{array}{l}1.04 \\
(0.89-1.22)\end{array}$ & 0.643 & $0 \%$ & $0.80-1.24$ & $0.82-1.32$ & $0 \%$ & $21.1 \%$ & 4380 \\
\hline Received PPI (9 trials) & $\begin{array}{l}1.02 \\
(0.93-1.13)\end{array}$ & 0.647 & $\begin{array}{l}1.02 \\
(0.93-1.13)\end{array}$ & 0.619 & $0 \%$ & $0.82-1.28$ & $0.82-1.28$ & $0 \%$ & $28.5 \%$ & 2976 \\
\hline Received H2RA (18 trials) & $\begin{array}{l}0.97 \\
(0.83-1.14)\end{array}$ & 0.711 & $\begin{array}{l}0.99 \\
(0.83-1.18)\end{array}$ & 0.921 & $0 \%$ & $0.74-1.28$ & $0.73-1.35$ & $0 \%$ & $22.3 \%$ & 4089 \\
\hline Received EN (12 trials) & $\begin{array}{l}1.05 \\
(0.96-1.16)\end{array}$ & 0.264 & $\begin{array}{l}1.05 \\
(0.96-1.16)\end{array}$ & 0.254 & $0 \%$ & $0.88-1.27$ & $0.88-1.27$ & $0 \%$ & $28 \%$ & 3048 \\
\hline $\begin{array}{l}\text { Did not receive EN (12 } \\
\text { trials) }\end{array}$ & $\begin{array}{l}0.85 \\
(0.71-1.02)\end{array}$ & 0.077 & $\begin{array}{l}0.82 \\
(0.66-1.02)\end{array}$ & 0.075 & $0 \%$ & $0.63-1.15$ & $0.58-1.17$ & $0 \%$ & $21.7 \%$ & 4230 \\
\hline
\end{tabular}

Pneumonia 
Table 1 The conventional meta-analysis and trial sequential analysis using random-effects and fixed-effects for all outcomes (Continued)

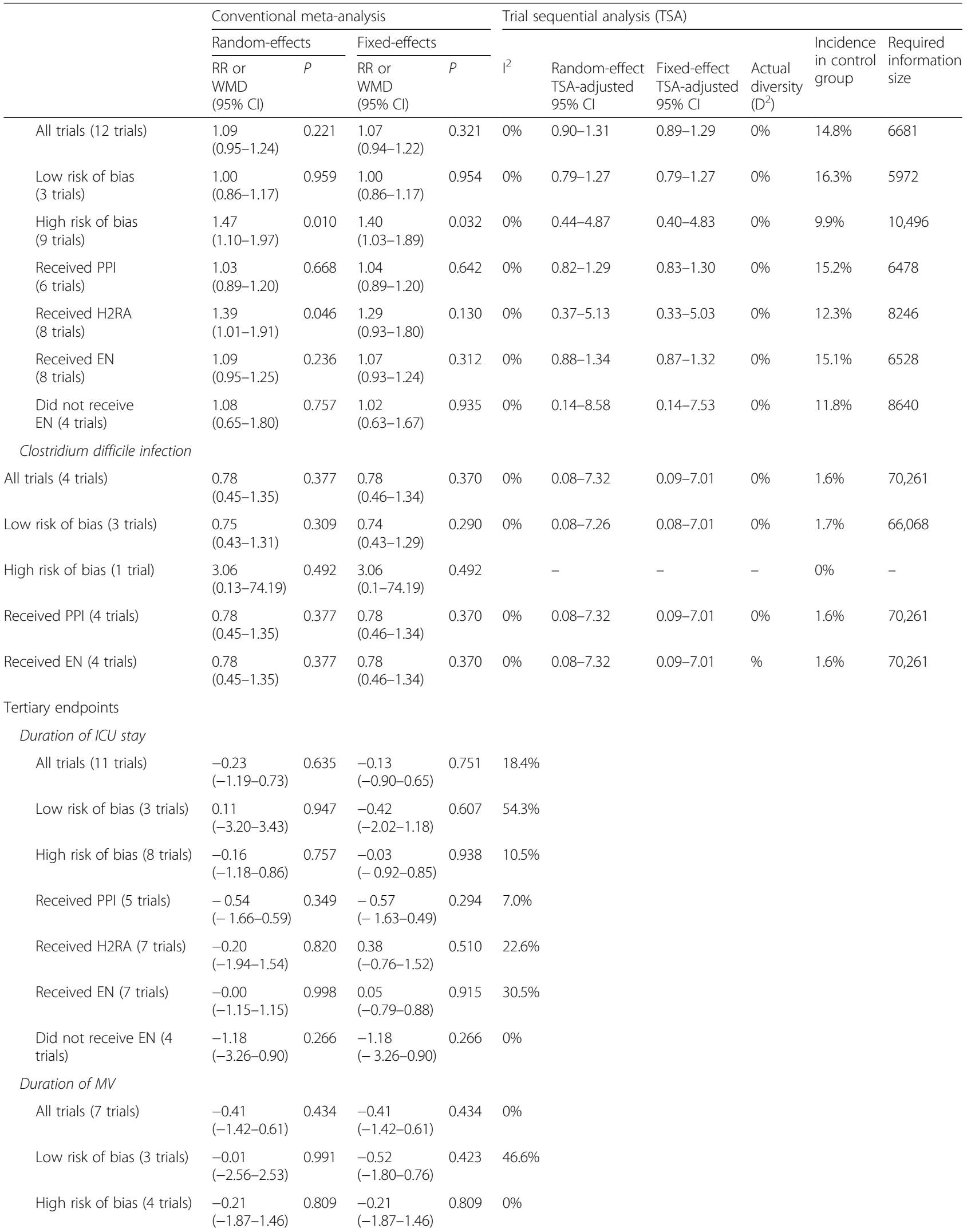


Table 1 The conventional meta-analysis and trial sequential analysis using random-effects and fixed-effects for all outcomes (Continued)

\begin{tabular}{|c|c|c|c|c|c|c|c|c|c|c|}
\hline & \multicolumn{4}{|c|}{ Conventional meta-analysis } & \multicolumn{6}{|c|}{ Trial sequential analysis (TSA) } \\
\hline & \multicolumn{2}{|c|}{ Random-effects } & \multicolumn{2}{|l|}{ Fixed-effects } & \multirow[b]{2}{*}{$1^{2}$} & \multirow[b]{2}{*}{$\begin{array}{l}\text { Random-effect } \\
\text { TSA-adjusted } \\
95 \% \mathrm{Cl}\end{array}$} & \multirow[b]{2}{*}{$\begin{array}{l}\text { Fixed-effect } \\
\text { TSA-adjusted } \\
95 \% \mathrm{Cl}\end{array}$} & \multirow[b]{2}{*}{$\begin{array}{l}\text { Actual } \\
\text { diversity } \\
\left(D^{2}\right)\end{array}$} & \multirow{2}{*}{$\begin{array}{l}\text { Incidence } \\
\text { in control } \\
\text { group }\end{array}$} & \multirow{2}{*}{$\begin{array}{l}\text { Required } \\
\text { information } \\
\text { size }\end{array}$} \\
\hline & $\begin{array}{l}\text { RR or } \\
\text { WMD } \\
(95 \% \mathrm{Cl})\end{array}$ & $P$ & $\begin{array}{l}\text { RR or } \\
\text { WMD } \\
(95 \% \text { Cl) }\end{array}$ & $P$ & & & & & & \\
\hline $\begin{array}{l}\text { Received PPI } \\
\text { (4 trials) }\end{array}$ & $\begin{array}{l}-0.04 \\
(-1.63-1.55)\end{array}$ & 0.965 & $\begin{array}{l}-0.35 \\
(-1.55-0.85)\end{array}$ & 0.567 & $20.8 \%$ & & & & & \\
\hline $\begin{array}{l}\text { Received H2RA } \\
\text { (4 trials) }\end{array}$ & $\begin{array}{l}-0.57 \\
(-2.57-1.43)\end{array}$ & 0.574 & $\begin{array}{l}-0.55 \\
(-2.47-1.37)\end{array}$ & 0.576 & $5.6 \%$ & & & & & \\
\hline $\begin{array}{l}\text { Received EN } \\
(6 \text { trials })\end{array}$ & $\begin{array}{l}-0.25 \\
(-1.43-0.93)\end{array}$ & 0.676 & $\begin{array}{l}-0.37 \\
(-1.40-0.66)\end{array}$ & 0.481 & $11.5 \%$ & & & & & \\
\hline $\begin{array}{l}\text { Did not receive EN } \\
\text { (1 trial) }\end{array}$ & $\begin{array}{l}-2.00 \\
(-8.83-4.83)\end{array}$ & 0.566 & $\begin{array}{l}-2.00 \\
(-8.83-4.83)\end{array}$ & 0.566 & - & & & & & \\
\hline
\end{tabular}

ICU intensive care unit, PPI proton pump inhibitors, H2RA histamine2 receptor antagonists, EN enteral nutrition, $M V$ mechanical ventilation, GI gastrointestinal TSA trial sequential analysis, $W M D$ weighted mean difference, $R R$ relative risk, $C l$ confidence interval

"- "means unavailable data due to too little information used

TSA was conducted with an adjusted type I error of $3.3 \%$ for the primary endpoints and $2.5 \%$ for the secondary endpoints, power of $80 \%$, $D^{2}$ suggested by the included trials, relative risk reduction of $20 \%$, two-tailed. If the actual measured $D^{2}$ was zero, a $D^{2}$ of $25 \%$ was used, because in this case heterogeneity would most likely increase when further studies are included

25-29, 31, 32, 34, 38, 40-42, 44], of which 9 trials [9, 13, $25,28,29,34,38,41,42]$ used ranitidine and 11 trials [7, $8,10-12,26,27,31,32,40,44]$ used cimetidine. There are 6 trials in which the intervention group received PPI as SUP $[8,24,30,33,36,43]$, and it is worth mentioning that the trial by Gursoy et al. [33] set 5 intervention groups and one control group, all intervention groups received PPI, hence we combined the intervention groups into a single group to compare with the control group. Notably, the trials by Kantorova et al. [35] and Liu et al. [37] set 2 intervention groups in which one group used PPI and another group used H2RA, therefore the control group was divided evenly into two groups to make two comparisons. Additionally, as to the trial by Powell et al. [39] which have 3 intervention groups (one group received H2RA and two groups received PPI), we combined the two groups received PPI into a single group, and divided the control group into two groups. In all included trials, the dosage, duration of drug used and drugdelivery methods were largely different in the intervention group. The control groups received placebo [10-13, 18, 24, $27-35,37,39,40,43]$ or no prophylaxis [7-9, 25, 26, 36, 38, $41,42,44]$. The subjects in 16 trials did not receive EN [7-9, 11-13, 28, 29, 31-34, 37, 39, 41, 44], however part or all patients received EN in the remaining 13 trials [10, 18, 24-27, $30,35,36,38,40,42,43]$.

\section{Risk of bias assessment}

The full details of the risk of bias assessment of each included trials were presented in Table 2. There were 4 studies adjudicated as low risk of bias in all domains [18, $24,30,34]$, and all other studies were deemed overall high risk of bias due to at least one domain with an unclear or high risk of bias.

\section{Analysis of the primary outcomes The clinically important Gl bleeding}

There were 11 studies [10, 11, 18, 24, 26, 28, 30, 34-36, 43 ], consisting of 4521 participants, reported data on the clinically important GI bleeding. The pooled results demonstrated that use of SUP was associated with a decreased risk of the clinically important GI bleeding $(\mathrm{RR}=$ $0.58,95 \%$ CI: $0.42-0.81, P=0.001, \mathrm{I}^{2}=0 \%$ ), this benefit was also found in sub-analysis of trials with low risk of bias $\left(\mathrm{RR}=0.64,95 \% \mathrm{CI}: 0.45-0.92, P=0.017 ; \mathrm{I}^{2}=0 \%\right)$ (Fig. 2.A), trials used PPI ( $R R=0.61,95 \%$ CI: $0.43-0.88$, $P=0.008 ; \mathrm{I}^{2}=0 \%$ ) (Fig. 2.B), and trials received $\mathrm{EN}$ $\left(\mathrm{RR}=0.61,95 \% \mathrm{CI}: 0.44-0.85, P=0.004 ; \mathrm{I}^{2}=0 \%\right.$ ) (Fig. 2.C), but not in trials used H2RA and trials did not receive EN. However, the results from TSA showed that the Z-curve just crossed the conventional boundary for benefit, but not the trial sequential monitoring boundary for benefit (Fig. 3, and in Additional file 1: Figure S1), indicated that it still lack of sufficient evidence to favor a $20 \%$ relative risk reduction in the risk of clinically important GI bleeding with use of SUP.

\section{The overt Gl bleeding}

There were 27 studies [7-13, 18, 24-28, 30-32, 34-44], with 30 comparisons, including 5919 participants, reported available data regarding overt GI bleeding. The pooled RR from the conventional meta-analysis for overt GI bleeding in all trials was 0.48 (95\% CI: 0.36-0.63, $P<$ $\left.0.001 ; \mathrm{I}^{2}=34.6 \%\right)$, the TSA showed that the trial sequential monitoring boundary for benefit was crossed with TSA-adjusted CI from 0.31 to $0.75\left(\mathrm{D}^{2}=62 \%\right)$ (Fig. 4), indicating a firm evidence on the beneficial effect of SUP on overt GI bleeding. In the sub-analyses of trials based on the trials quality (Fig. 5.A), the type of SUP used (Fig. 


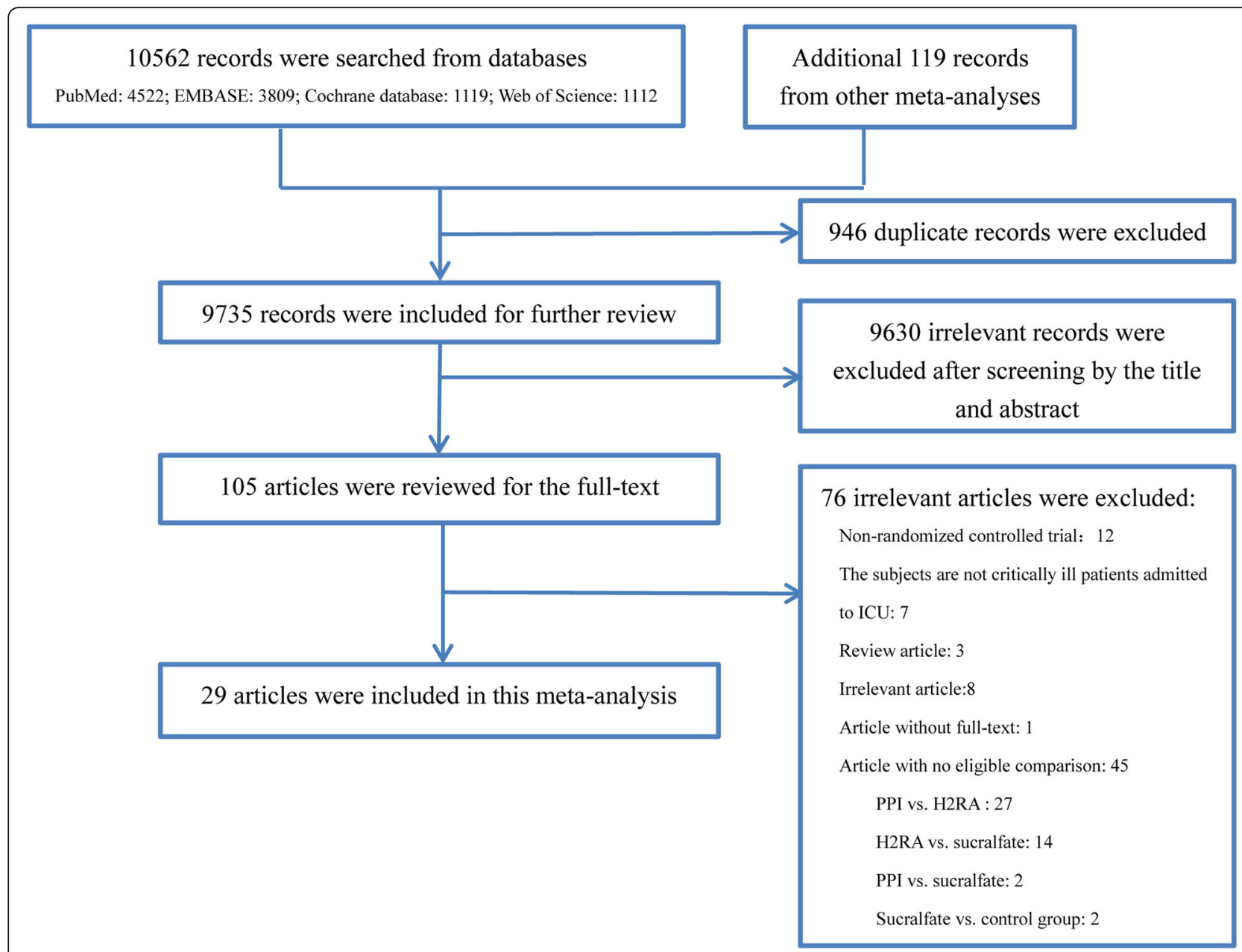

Fig. 1 The PRISMA flowchart of the study selection process

5.B), and whether EN was used (Fig. 5.C), we also found a significant reduction in the incident of overt GI bleeding with use of SUP. Furthermore, TSA showed that the Z-curve crossed the trial sequential monitoring boundary for benefit in trials did not receive EN (Fig. 6.A), in trials used PPI as SUP (Additional file 1: Figure S2.A), and in trials used H2RA as SUP (Additional file 1: Figure S2.B). However, the TSA for trials adjudicated as low risk of bias (Fig. 6.B) and trials received EN (Fig. 6.C) revealed a neutral benefit in reducing the risk of overt GI bleeding, thus more evidence is required to confirm this benefits in this case.

\section{Analysis of the secondary outcomes}

There are 24 RCTs [7, 10-12, 18, 24-26, 28-30, 32-44] included in analysis for all-cause mortality, the conventional meta-analysis indicated that SUP was not associated with a lower mortality compared with the control group, regardless of the trials quality (Additional file 1: Figure S3.A), the type of SUP used (Additional file 1: Figure S3.B), and whether EN was used (Additional file
1: Figure S3.C). These results was firmly confirmed by TSA in which the Z-curve reached the futility area, indicating that there are sufficient events in current trials to reject a $20 \%$ relative risk reduction in mortality with use of SUP (Additional file 1: Figure S4). However, it still lack of sufficient evidence on the effects of SUP on mortality in patients did not receive EN (Additional file 1: Figure S4.F), because the Z-curve did not cross any boundaries.

In the meta-analysis of 12 trials [11, 12, 18, 24-26, $34-38,43]$ refered to data on pneumonia, we found that administraion of SUP was not accompanied by increased risk of pneumonia, TSA further confirmed this result with the Z-curve crossing the boundary for futility (Additional file 1: Figure S5.A). Also, negtive results were observed in sub-analysis of trials with low risk of bias (Additional file 1: Figure S6.A), in trials used PPI as SUP (Addtional file 1: Figure S6.B), in trials used H2RA as SUP (Additional file 1: Figure S6.B), in trials with use of EN (Additional file 1: Figure S6.C), or in trials without use of EN (Additional file 1: Figure S6.C), TSA suggested 
Table 2 Assessment of the risk of bias of each included trials

\begin{tabular}{|c|c|c|c|c|c|c|c|c|}
\hline $\begin{array}{l}\text { First author } \\
\text { /Publication year }\end{array}$ & $\begin{array}{l}\text { Adequate } \\
\text { Sequence } \\
\text { Generation }\end{array}$ & AllocationConcealment & $\begin{array}{l}\text { Blinding of participants } \\
\text { and personnel }\end{array}$ & $\begin{array}{l}\text { Blinding of } \\
\text { outcome } \\
\text { assessment }\end{array}$ & $\begin{array}{l}\text { Incomplete } \\
\text { Outcome } \\
\text { Data }\end{array}$ & $\begin{array}{l}\text { Selective } \\
\text { reporting }\end{array}$ & $\begin{array}{l}\text { Other } \\
\text { Bias }\end{array}$ & $\begin{array}{l}\text { Overall risk } \\
\text { of bias }\end{array}$ \\
\hline Alhazzani/2017 & $L$ & $\mathrm{~L}$ & $\mathrm{~L}$ & L & $\mathrm{L}$ & L & $\mathrm{L}$ & $\mathrm{L}$ \\
\hline Apte/1992 & unclear & unclear & $\mathrm{H}$ & unclear & L & $\mathrm{L}$ & $\mathrm{H}$ & $\mathrm{H}$ \\
\hline Basso/1981 & $\mathrm{L}$ & unclear & $\mathrm{H}$ & L & $\mathrm{H}$ & $\mathrm{H}$ & unclear & $\mathrm{H}$ \\
\hline $\begin{array}{l}\text { Ben-Menachem/ } \\
1994\end{array}$ & $\mathrm{~L}$ & $L$ & $\mathrm{H}$ & L & $\mathrm{H}$ & $L$ & $\mathrm{~L}$ & $\mathrm{H}$ \\
\hline $\begin{array}{l}\text { van den Berg } \\
\text { /1985 }\end{array}$ & unclear & unclear & $\mathrm{L}$ & L & $\mathrm{L}$ & $\mathrm{H}$ & $\mathrm{L}$ & $\mathrm{H}$ \\
\hline Burgess/1995 & $\mathrm{L}$ & unclear & $\mathrm{L}$ & L & $\mathrm{H}$ & $\mathrm{L}$ & unclear & $\mathrm{H}$ \\
\hline Calvet/1998 & unclear & L & $\mathrm{L}$ & L & $L$ & $\mathrm{H}$ & $\mathrm{L}$ & $\mathrm{H}$ \\
\hline Darlong/2003 & unclear & unclear & $\mathrm{H}$ & unclear & $\mathrm{H}$ & $\mathrm{H}$ & $\mathrm{L}$ & $\mathrm{H}$ \\
\hline El-Kersh/2018 & $\mathrm{L}$ & L & $\mathrm{L}$ & L & L & $L$ & L & $\mathrm{L}$ \\
\hline Friedman/1982 & unclear & unclear & $\mathrm{L}$ & L & $L$ & $\mathrm{H}$ & $\mathrm{H}$ & $\mathrm{H}$ \\
\hline Groll/1986 & unclear & unclear & $\mathrm{L}$ & $L$ & $L$ & $L$ & $\mathrm{H}$ & $\mathrm{H}$ \\
\hline Gursoy/2008 & $L$ & unclear & L & L & L & L & L & $\mathrm{H}$ \\
\hline Halloran/1980 & L & unclear & $\mathrm{L}$ & L & $L$ & $L$ & $\mathrm{H}$ & $\mathrm{H}$ \\
\hline Hanisch/1998 & $L$ & $\mathrm{~L}$ & $\mathrm{~L}$ & $\mathrm{~L}$ & $L$ & $L$ & $L$ & $\mathrm{~L}$ \\
\hline Kantorova/2004 & $L$ & L & unclear & L & $L$ & $L$ & unclear & $\mathrm{H}$ \\
\hline Karlstadt/1990 & unclear & unclear & $\mathrm{L}$ & L & L & L & unclear & $\mathrm{H}$ \\
\hline Krag/2018 & L & L & $\mathrm{L}$ & L & L & L & L & $\mathrm{L}$ \\
\hline Lin/2016 & unclear & unclear & unclear & unclear & L & L & L & $\mathrm{H}$ \\
\hline Liu/2013 & L & unclear & unclear & unclear & L & L & unclear & $\mathrm{H}$ \\
\hline Macdougall/1977 & unclear & unclear & $\mathrm{H}$ & $\mathrm{H}$ & $L$ & $L$ & unclear & $\mathrm{H}$ \\
\hline Martin/1993 & unclear & unclear & $\mathrm{L}$ & L & L & $L$ & $\mathrm{H}$ & $\mathrm{H}$ \\
\hline Metz/1993 & $L$ & $L$ & $\mathrm{~L}$ & $L$ & $L$ & $\mathrm{H}$ & $\mathrm{H}$ & $\mathrm{H}$ \\
\hline Nourian/2018 & $L$ & unclear & unclear & unclear & L & $L$ & L & $\mathrm{H}$ \\
\hline Peura/1985 & unclear & unclear & $\mathrm{L}$ & L & $L$ & L & L & $\mathrm{H}$ \\
\hline Powell/1993 & $\mathrm{H}$ & $\mathrm{H}$ & $\mathrm{H}$ & unclear & L & L & L & $\mathrm{H}$ \\
\hline Reusser/1990 & unclear & unclear & $\mathrm{H}$ & unclear & $L$ & $L$ & L & $\mathrm{H}$ \\
\hline $\begin{array}{l}\text { Ruiz-Santana/ } \\
1991\end{array}$ & unclear & unclear & $\mathrm{H}$ & $\mathrm{H}$ & $\mathrm{H}$ & L & L & $\mathrm{H}$ \\
\hline $\begin{array}{l}\text { Selvanderan/ } \\
2016\end{array}$ & $L$ & unclear & $\mathrm{L}$ & L & $L$ & $L$ & L & $\mathrm{H}$ \\
\hline Zinner/1981 & L & $\mathrm{H}$ & $\mathrm{H}$ & unclear & $\mathrm{H}$ & unclear & L & $\mathrm{H}$ \\
\hline
\end{tabular}

$L$ low, $H$ high

that the pooled results were robust in subgroup of trials with low risk of bias (Additional file 1: Figure S5.B), trials received PPI (Additional file 1: Fig. S5.C), and trials with use of EN (Additional file 1: Figure S5.E).

There are 4 trials presented data on CDI [18, 24, 30, 43], all of them received PPI and EN, three of them was judged have low risk of bias. There was no difference in the incident of CDI between SUP group and control group. Subanalysis of trials with low risk of bias also revealed a neutral effect of SUP on the incident of CDI (Additional file 1: Figure S7). However, TSA demonstrated that the Z-curve crossed no boundaries (Additional file 1: Figure S8), indicating that this results could be changed when more studies were incuded.

\section{Analysis of the tertiary outcomes}

There are 11 studies reported data on the duration of ICU stay $[12,24,26,30,33-35,38,41-43]$ and 7 studies [24, 26, $30,34,35,38,43]$ reported data on the duration of MV, the pooled results suggested that use of SUP could not result in a significant reduction in the duration of ICU stay (Additional file 1: Figure S9) and duration of MV (Additional file 1: Figure S10) when compared with placebo or no 

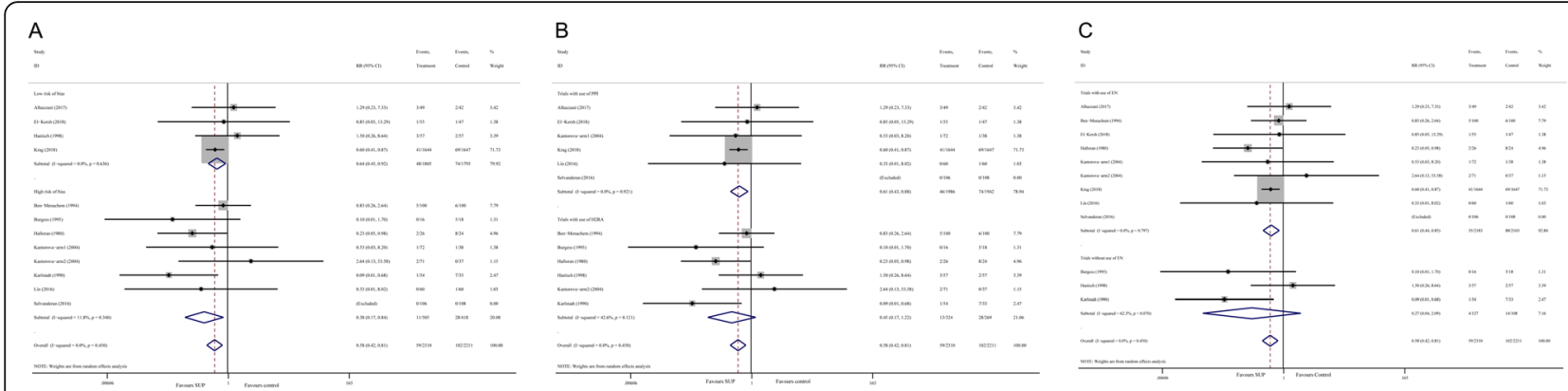

Fig. 2 Forest plot of subgroup analysis for the clinically important Gl bleeding based on the trials quality (panel a), the type of SUP used (panel b), and whether EN was used (panel c). SUP stress ulcer prophylaxis; Gl gastrointestinal; RR relative risk; PPI proton pump inhibitors; H2RA histamine 2 receptor antagonists; EN enteral nutrition

prophylaxis, regardless of the trials quality, the type of SUP used, and whether EN was used.

\section{Analysis for publication bias}

We assessed the publication bias for the primary outcomes. All the funnel plots were visually symmetrical (Fig. 7). The Begg's and Egger's tests for the clinically important GI bleeding $(P=0.436$ and $P=0.395$, respectively) and for overt GI bleeding $(P=0.617$ and $P=0.280$, respectively) revealed no evidence of publication bias.

\section{Discussion}

In this meta-analysis, we found that use of SUP, with PPI or H2RA, was associated with a reduced incident of clinically important GI bleeding and overt GI bleeding, but had no effects on the all-cause mortality, incident of pneumonia and CDI, and duration of MV and ICU stay. After adjustment with TSA, we could firmly conclude that SUP had beneficial effects in reducing the incident of overt GI bleeding, this benefit was confirmed in patients who did not receive EN, but not in those who received EN, and SUP had also no effects on the mortality and pneumonia. However, it still needs more evidence to confirm the effects of SUP on others clinical outcomes.

Critically ill patients in the ICU always suffer from a series of change in hemodynamics, such as hypoxia, hypotension, stress, etc., these conditions can cause a reduction in GI mucosal blood flow and lead to a collapse of defense mechanisms of GI mucosa [45, 46], thus resulting in stress-related ulcer and subsequent GI bleeding. As to critically ill patients who are at high risk of GI bleeding, pharmacy prophylaxis is the first-line therapy for preventing stress-related ulcer, PPI and H2RA are the most common drugs for SUP. Over the past decades, nearly $30 \mathrm{RCTs}$ were successively conducted to investigate the efficacy of SUP with PPI or H2RA in ICU patients, and the results from the most recent meta-analyses $[15,16]$ favor the use of SUP with PPI or H2RA in critically ill patients, however, the quality of evidence is low and the number of subjects is

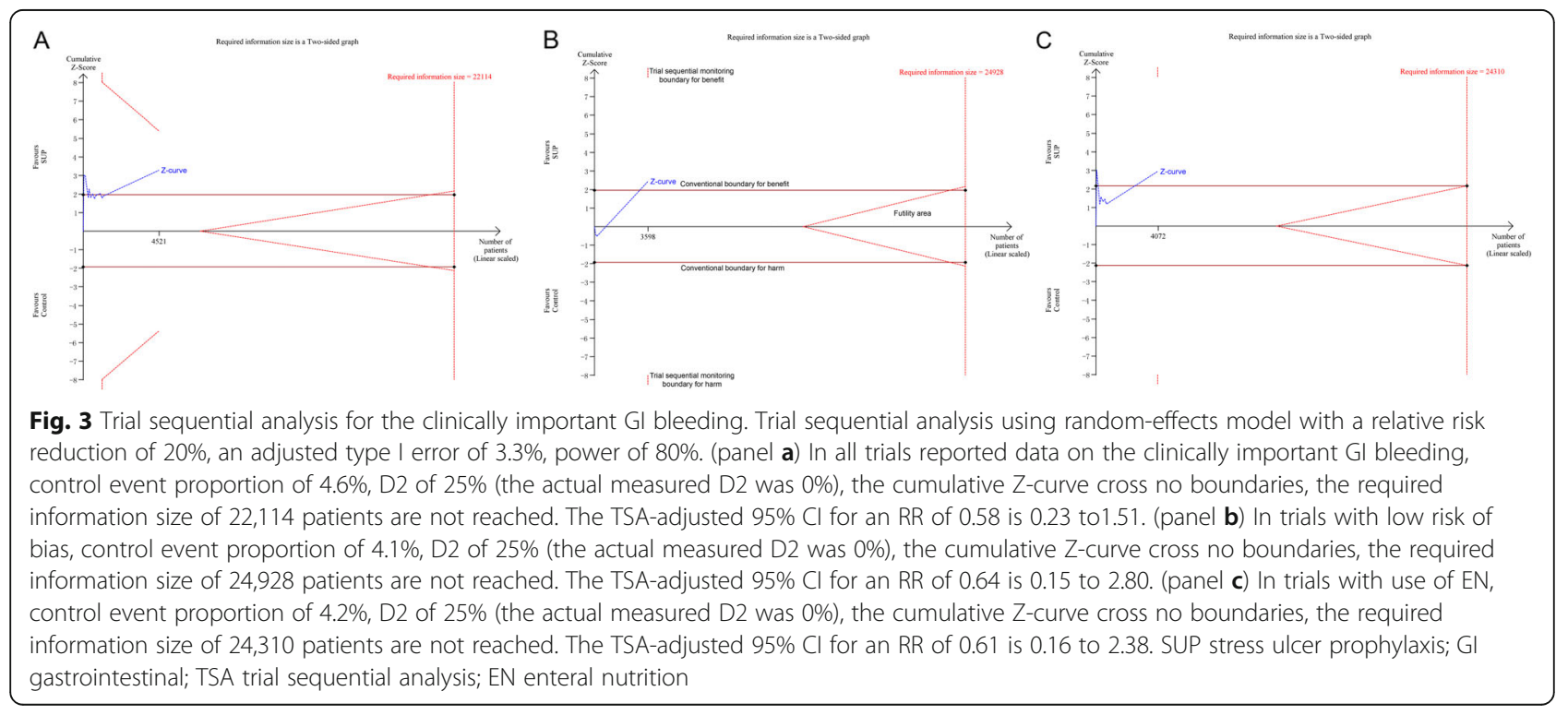



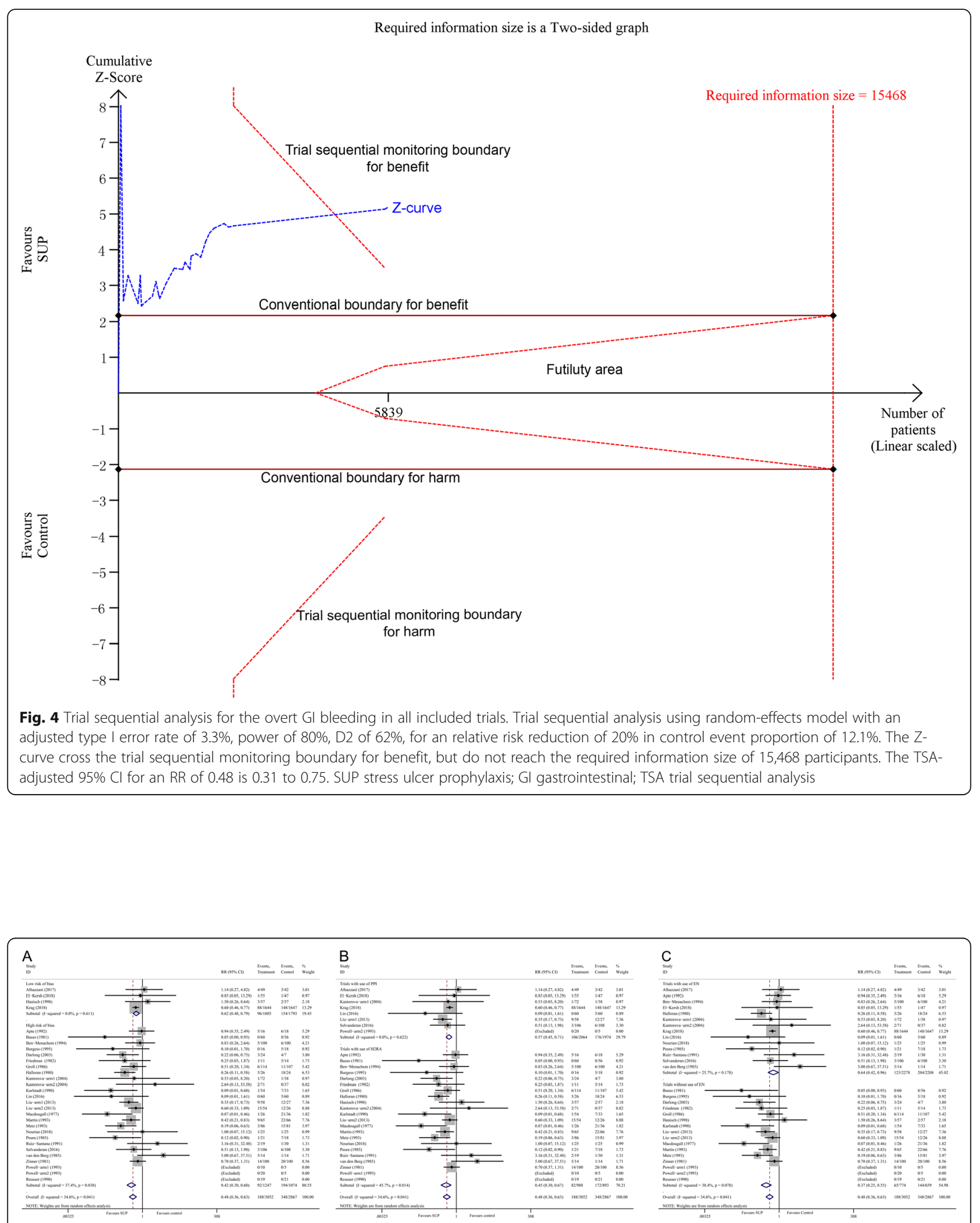

Fig. 5 Forest plot of subgroup analysis for the overt Gl bleeding based on the trials quality (panel a), the type of SUP used (panel b), and whether EN was used (panel c). SUP stress ulcer prophylaxis; Gl gastrointestinal; RR relative risk; PPI proton pump inhibitors; H2RA histamine 2 receptor antagonists; EN enteral nutrition 

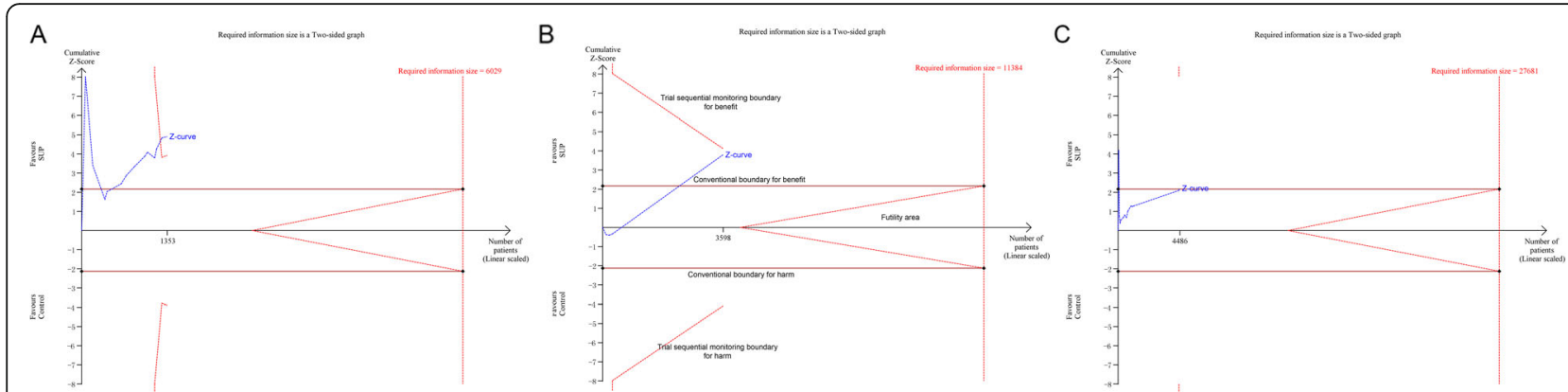

Fig. 6 Trial sequential analysis for the overt GI bleeding. Trial sequential analysis using random-effects model with a relative risk reduction of 20\%, an adjusted type I error of 3.3\%, power of 80\%. (panel a) In trials did not receive EN, control event proportion of 21.9\%, D2 of 52\%, the cumulative Z-curve cross cross the trial sequential monitoring boundary for benefit, the required information size of 6029 patients are not reached. The TSA-adjusted $95 \% \mathrm{Cl}$ for an RR of 0.37 is 0.22 to 0.63 . (panel b) In trials with low risk of bias, control event proportion of $8.6 \%$, D2 of 25\% (the actual measured D2 was 0\%), the cumulative Z-curve cross no boundaries, the required information size of 11,384 patients are not reached. The TSA-adjusted $95 \% \mathrm{Cl}$ for an RR of 0.62 is 0.37 to 1.04. (panel c) In trials with use of EN, control event proportion of 9.2\%, D2 of 71\%, the cumulative Z-curve cross no boundaries, the required information size of 27,681 patients are not reached. The TSA-adjusted $95 \% \mathrm{Cl}$ for an RR of 0.64 is 0.12 to 3.35 . SUP stress ulcer prophylaxis; GI gastrointestinal; TSA trial sequential analysis; EN enteral nutrition

insufficient. Accordingly, the Surviving Sepsis Campaign guidelines [47] for septic shock just weakly recommended use of PPI or H2RA as SUP for patients with sepsis or septic shock who have risk factors for GI bleeding. Moreover, the trial by Apte et al. [25] revealed a higher incidence of pneumonia in patients received H2RA, some observational studies [6, 48, 49] also found an increased risk of infectious complications, including pneumonia and CDI, in critically ill patients receiving SUP, thus concerns on the balance between benefits and harms of SUP raised in recent years.

In this meta-analysis, we found that administration of PPI or H2RA has benefits in reducing the risk of overt GI bleeding, and might reduce the risk of clinically important GI bleeding, but has no benefits for all-cause mortality, these results were similar with the study by Reynolds et al.
[15] and by Karg et al. [50]. This finding caused our question that the benefit of SUP in preventing GI bleeding cannot be translated into beneficial effect on mortality. The potential explation includes that overt GI bleeding indicates slight haemorrhage in GI tract without influence on hemodynamics and did not need transfusion or surgical intervention, thus the reduction in overt GI bleeding might not produce a benefit in mortality. Additionally, Clostridium difficile-associated diarrhea has become an increasing challenge in ICU, a massive fluid loss would lead to changes of hemodynamics and disorder of internal environment, and thus, result in a high mortality and prolonged ICU stay $[6,50]$. Furthermore, gastric acid is a natural barrier against pathogens, suppressing secretion of gastric acid by PPI or H2RA will break this barrier and results in a bacterial overgrowth and colonization, which will cause
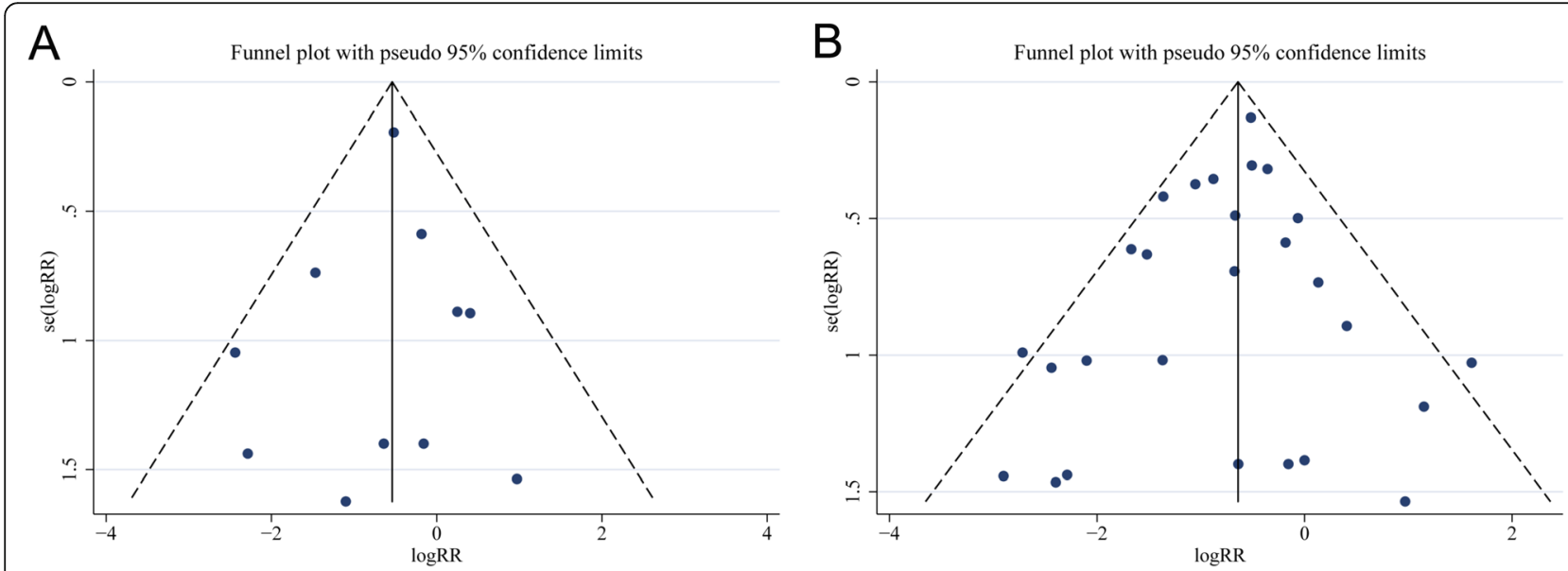

Fig. 7 Funnel plots for evaluating the publication bias of included trials for theclinically important Gl bleeding (Panel a) and overt Gl bleeding (Panel b). Both funnel plots are visually symmetric, and the Begg's and Egger's tests reveals no significant publication bias. RR relative risk; Gl Gl gastrointestinal 
infectious compilcations [51]. Therefore, the above adverse effects might counterbalance the benefit in mortality resulted from the decreased risk of clinically important GI bleeding with use of SUP. In addition, we also found a beneficial effect of SUP on overt GI bleeding among patients who did not receive EN, however, this benefit were not sure in patients who received EN, the study by Huang et al. [17] also found that SUP is not beneficial for ICU patients received EN to reduce the GI bleeding. Nowadays, EN has been recongnized as the first choice of nutrition routine for critically ill patients, EN is expected to prevent GI bleeding by increasing GI mucosa blood flow and limiting the bacterial translocation through maintenance of gut integrity [52-55]. Previous studies has demonstrated that EN might provide sufficient prophylaxis against stressrelated GI bleeding $[56,57]$, there are even opinions that EN might be more effective than SUP in preventing GI bleeding [58]. Therefore, SUP maybe more effective in reducing overt GI bleeding in patients who did not receive EN than those who received EN.

Two strengths in this meta-analysis should be mentioned. Firstly, our meta-analysis has a larger sample size. Different from the previous meta-analysis [14-17], our study included the SUP-ICU trial [18], in which the number of the subject is more than 3000, which are larger than the total number of subjects in all previous trials. Therefore, our meta-analysis with a larger sample size would decrease the sampling errors and selective bias to some extent and reveal the outcome effects more objectively [21]. In addition, TSA suggests that sufficient events had been accrued in the current trials to draw a firm conclusion on the effect of SUP on the risk of overt GI bleeding, this benefit was more obvious in patients did not receive EN, however, convinced evidence regarding the efficacy of SUP in patients received EN are still lacking, hence this results could be referenced to guide future trial to focus on the use of SUP in critically ill patients received EN. Secondly, a more reasonable method was implemented in our meta-analysis to handle the data in trials with multiple intervention groups. As to trials with multiple intervention groups, the optimal approach recommended by the Cochrane Collaboration [20] is to combine all relevant intervention groups into a single group. However, in the meta-analyses by Reynolds et al. [15] and by Krag et al. [59], they compared the multiple intervention groups with the "shared" control group and then simply entered multiple comparisons into meta-analysis, this approach should be avoided on account of a unit-of-analysis error, which was associated with the unaddressed correlation between the estimated intervention effects from multiple comparisons [20]. To overcome this error, we combined all intervention groups into a single group to compare with the "shared" control group if the intervention groups received the same type of SUP, or split the "shared" control group into multiple groups to make multiple pair-wise comparisons if the intervention groups received a different type of SUP. We also adjusted the thresholds for significance based on the number of outcomes because of problems with multiplicity, this is another methodological strength in our study.

However, there are several limitations in our study. First, subgroup analysis was conducted based on the type of SUP, the trials quality, and status of EN, not for other variables. We noticed that there was significant statistical heterogeneity in the analysis for the overt GI bleeding, and the clinical heterogeneity between studies is substantial, the dosage, route of administration, infusion duration of drug used, and ICU setting are varied between the included trials, unfortunately, we did not perform a sub-analysis based on these factors. Additionally, there is a big difference in the number of subjects between included trials, the possible overestimation of effect size in studies with a small sample size should be considered when interpreting the results. Second, TSA in our study was performed for the primary and secondary outcomes, but not for the tertiary outcomes, cumulative meta-analysis of sparse data and repeated significance testing always lead to increased risk of random error, TSA could prevent this risk [23], hence the results of conventional meta-analyses for the tertiary outcomes should be interpreted carefully. Lastly, there was a considerable variation in the definition of overt GI bleeding, clinically important GI bleeding and pneumonia in some studies, this variation might be translated into statistical heterogeneity.

\section{Conclusions}

This meta-analysis with TSA firmly conclude that there are sufficient evidence in favor of the benefit of SUP in reducing the risk of overt GI bleeding in critically ill patients, those who did not receive EN might suffer from this benefit more obviously, future trials are unlikely to detect a $20 \%$ reduction in all-cause mortality and pneumonia, however, the effect of SUP on clinically important GI bleeding still needs more evidence to confirm.

\section{Supplementary information}

Supplementary information accompanies this paper at https://doi.org/10. 1186/s12876-019-1105-y.

Additional file 1: the supplementary materials regarding search strategy, reasons for exclusion of ineligible studies, detailed information on included studies, and supplementary tables and figures for analyzing the clinical outcomes.

\section{Abbreviations}

CDI: Clostridium difficile infection; Cl: Confidence interval; EN: Enteral nutrition; Gl: Gastrointestinal; H2RA: Histamine2 receptor antagonists; ICU: Intensive care unit; IQR: Interquartile rang; MV: Mechanical ventilation; PPI: Proton 
pump inhibitors;" RCTs: Randomized controlled trials; RR: Relative risk; SD: Standard deviation; SUP: Stress ulcer prophylaxis; TSA: Trial sequential analysis; WMD: Weighted mean difference

\section{Acknowledgments}

Xiaoyang Zhou wants to thanks his mother, Songying Zhou, for her meticulous care and attention, and strong courage.

\section{Authors' contributions}

$X Z$ designed the study, performed the literature search and data analysis, and drafted the manuscript. ZX and $\mathrm{CH}$ participated in the conception and design of the study, performed the quality assessment and helped to revise the manuscript. HF performed the literature search and drafted the manuscript. JX, PC and XH performed the study selection and statistical analysis and helped to draft the manuscript. BC and HW performed the data extraction and analysis, modified the language. All the authors have read and approved the final manuscript.

\section{Funding}

This work was supported by the grants from Zhejiang Medicine and Health Sciences Research Fund (No. 2019KY184). The funders had no role in the study design, data collection, and analysis, decision to publish, or preparation of the manuscript.

\section{Availability of data and materials}

All data generated or analyzed during this study are included in this published article (and its supplementary information files).

\section{Ethics approval and consent to participate}

Not applicable.

\section{Consent for publication}

Not applicable. The authors declare that no patient data (details, images or videos relating to individual participants) are included in this article.

\section{Competing interests}

The authors declare that they have no competing interests.

\section{Author details}

${ }^{1}$ Department of Intensive Care Medicine, HwaMei Hospital, University Of Chinese Academy of Sciences, Ningbo 315000, Zhejiang, China. ${ }^{2}$ Department of Emergency, Ningbo Yinzhou No.2 Hospital, Ningbo 315000, Zhejiang, China. ${ }^{3}$ Department of Intensive Care Medicine, Zhejiang Hospital, Hangzhou 310000, Zhejiang, China

\section{Received: 28 August 2019 Accepted: 30 October 2019}

\section{Published online: 21 November 2019}

\section{References}

1. Cook DJ, Fuller HD, Guyatt GH, Marshall JC, Leasa D, Hall R, et al. Risk factors for gastrointestinal bleeding in critically ill patients. Canadian critical care trials group. N Engl J Med. 1994;330(6):377-81.

2. Krag M, Perner A, Wetterslev J, Wise MP, Borthwick M, Bendel S, et al. Prevalence and outcome of gastrointestinal bleeding and use of acid suppressants in acutely ill adult intensive care patients. Intensive Care Med. 2015;41(5):833-45

3. Krag M, Perner A, Møller MH. Stress ulcer prophylaxis in the intensive care unit. Curr Opin Crit Care. 2016;22(2):186-90.

4. García-Rayado G, Lanas A. Upper gastrointestinal bleeding in critically ill patients: proton-pump inhibitors, histamine-2 receptor antagonists or placebo? Many questions remain unanswered. Curr Med Res Opin. 2018; 34(11):1881-3.

5. Cook DJ, Griffith LE, Walter SD, Guyatt GH, Meade MO, Heyland DK, et al. The attributable mortality and length of intensive care unit stay of clinically important gastrointestinal bleeding in critically ill patients. Crit Care. 2001; 5(6):368-75

6. Buendgens L, Bruensing J, Matthes M, Dückers $H$, Luedde T, Trautwein C, et al. Administration of proton pump inhibitors in critically ill medical patients is associated with increased risk of developing Clostridium difficileassociated diarrhea. J Crit Care. 2014;29(4):696.e11-5.
7. Macdougall BR, Bailey RJ, Williams R. H2-receptor antagonists and antacids in the prevention of acute gastrointestinal haemorrhage in fulminant hepatic failure. Two controlled trials. Lancet. 1977;1(8012):617-9.

8. Basso N, Bagarani M, Materia A, Fiorani S, Lunardi P, Speranza V. Cimetidine and antacid prophylaxis of acute upper gastrointestinal bleeding in high risk patients. Controlled, randomized trial. Am J Surg. 1981;141(3):339-41.

9. Darlong V, Jayalakhsmi TS, Kaul HL, Tandon R. Stress ulcer prophylaxis in patients on ventilator. Trop Gastroenterol. 2003;24(3):124-8.

10. Halloran LG, Zfass AM, Gayle WE, Wheeler CB, Miller JD. Prevention of acute gastrointestinal complications after severe head injury: a controlled trial of cimetidine prophylaxis. Am J Surg. 1980;139(1):44-8.

11. Karlstadt RG, Iberti TJ, Silverstein J, Lindenberg L, Rright-Asare P. Rockhold Fw, et al. comparison of cimetidine and placebo for the prophylaxis of upper gastrointestinal bleeding due to stress-related gastric mucosal damage in the intensive care unit. J Intensive Care Med. 1990;5(1):26-32.

12. Martin LF, Booth FV, Karlstadt RG, Silverstein JH, Jacobs DM, Hampsey J, et al. Continuous intravenous cimetidine decreases stressrelated upper gastrointestinal hemorrhage without promoting pneumonia. Crit Care Med. 1993;21(1):19-30.

13. Metz CA, Livingston DH, Smith JS, Larson GM, Wilson TH. Impact of multiple risk factors and ranitidine prophylaxis on the development of stress-related upper gastrointestinal bleeding: a prospective, multicenter, double-blind, randomized trial. The ranitidine head injury study group. Crit Care Med. 1993;21(12):1844-9.

14. Alhazzani W, Alshamsi F, Belley-Cote E, Heels-Ansdell D, BrignardelloPetersen R, Alquraini M, et al. Efficacy and safety of stress ulcer prophylaxis in critically ill patients: a network meta-analysis of randomized trials. Intensive Care Med. 2018:44(1):1-11.

15. Reynolds PM, MacLaren R. Re-evaluating the utility of stress ulcer prophylaxis in the critically ill patient: a clinical scenario-based meta-analysis. Pharmacotherapy. 2018. https://doi.org/10.1002/phar.2172.

16. Toews I, George AT, Peter JV, Kirubakaran R, Fontes LES, Ezekiel JPB, et al. Interventions for preventing upper gastrointestinal bleeding in people admitted to intensive care units. Cochrane Database Syst Rev. 2018:6: CD008687.

17. Huang $H B$, Jiang W, Wang $C Y$, Qin HY, Du B. Stress ulcer prophylaxis in intensive care unit patients receiving enteral nutrition: a systematic review and meta-analysis. Crit Care. 2018;22(1):20.

18. Krag M, Marker S, Perner A, Wetterslev J, Wise MP, Schefold JC, et al. Pantoprazole in patients at risk for gastrointestinal bleeding in the ICU. N Engl J Med. 2018;379(23):2199-208.

19. Moher D, Shamseer $L$, Clarke M, Ghersi D, Liberati A, Petticrew M, et al. PRISMA-P Group. Preferred reporting items for systematic review and metaanalysis protocols (PRISMA-P) 2015 statement. Syst Rev. 2015;4:1.

20. Higgins JPT, Green S. Cochrane handbook for systematic reviews of interventions. http://www.cochrane-handbook.org/, The Cochrane Collaboration, 2011

21. Zhou X, Hu C, Yao L, Fan Z, Sun L, Wang Y, et al. Effect of adjunctive corticosteroids on clinical outcomes in adult patients with septic shock-a meta-analysis of randomized controlled trials and trial sequential analysis. J Crit Care. 2018:48:296-306

22. Jakobsen JC, Wetterslev J, Winkel P, Lange T, Gluud C. Thresholds for statistical and clinical significance in systematic reviews with meta-analytic methods. BMC Med Res Methodol. 2014;14:120.

23. Higgins JPT, Whitehead A, Simmonds M. Sequential methods for randomeffects meta-analysis. Stat Med. 2011;30(9):903-21.

24. Alhazzani W, Guyatt G, Alshahrani M, Deane AM, Marshall JC, Hall R. Et al; Canadian critical care trials group. Withholding pantoprazole for stress ulcer prophylaxis in critically ill patients: a pilot randomized clinical trial and meta-analysis. Crit Care Med. 2017;45(7):1121-9.

25. Apte NM, Karnad DR, Medhekar TP, Tilve GH, Morye S, Bhave GG. Gastric colonization and pneumonia in intubated critically ill patients receiving stress ulcer prophylaxis: a randomized, controlled trial. Crit Care Med. 1992; 20(5):590-3.

26. Ben-Menachem T, Fogel R, Patel RV, Touchette M, Zarowitz BJ, Hadzijahic N, et al. Prophylaxis for stress-related gastric hemorrhage in the medical intensive care unit. A randomized, controlled, single-blind study. Ann Intern Med. 1994:121(8):568-75.

27. van den Berg B, van Blankenstein M. Prevention of stress-induced upper gastrointestinal bleeding by cimetidine in patients on assisted ventilation. Digestion. 1985;31(1):1-8. 
28. Burgess P, Larson GM, Davidson P, Brown J, Metz CA. Effect of ranitidine on intragastric $\mathrm{pH}$ and stress-related upper gastrointestinal bleeding in patients with severe head injury. Dig Dis Sci. 1995;40(3):645-50.

29. Calvet X, Baigorri F, Duarte M, Joseph D, Saura P, Mas A, et al. Effect of ranitidine on gastric intramucosal $\mathrm{pH}$ in critically ill patients. Intensive Care Med. 1998;24(1):12-7.

30. El-Kersh K, Jalil B, McClave SA, Cavallazzi R, Guardiola J, Guilkey K, et al. Enteral nutrition as stress ulcer prophylaxis in critically ill patients: a randomized controlled exploratory study. J Crit Care. 2018;43:108-13.

31. Friedman CJ, Oblinger MJ, Suratt PM, Bowers J, Goldberg SK, Sperling MH, et al. Prophylaxis of upper gastrointestinal hemorrhage in patients requiring mechanical ventilation. Crit Care Med. 1982;10(5):316-9.

32. Groll A, Simon JB, Wigle RD, Taguchi K, Todd RJ, Depew WT. Cimetidine prophylaxis for gastrointestinal bleeding in an intensive care unit. Gut. 1986; 27(2):135-40.

33. Gursoy $\mathrm{O}$, Memiş $\mathrm{D}$, Sut $\mathrm{N}$. Effect of proton pump inhibitors on gastric juice volume, gastric $\mathrm{pH}$ and gastric intramucosal $\mathrm{pH}$ in critically ill patients : a randomized, double-blind, placebo-controlled study. Clin Drug Investig. 2008;28(12):777-82.

34. Hanisch EW, Encke A, Naujoks F, Windolf J. A randomized, double-blind trial for stress ulcer prophylaxis shows no evidence of increased pneumonia. Am J Surg. 1998;176(5):453-7.

35. Kantorova I, Svoboda P, Scheer P, Doubek J, Rehorkova D, Bosakova H, et al. Stress ulcer prophylaxis in critically ill patients: a randomized controlled trial. Hepatogastroenterology. 2004;51(57):757-61.

36. Lin CC, Hsu YL, Chung CS, Lee TH. Stress ulcer prophylaxis in patients being weaned from the ventilator in a respiratory care center: a randomized control trial. J Formos Med Assoc. 2016;115(1):19-24

37. Liu BL, Li B, Zhang X, Fei Z, Hu SJ, Lin W, et al. A randomized controlled study comparing omeprazole and cimetidine for the prophylaxis of stressrelated upper gastrointestinal bleeding in patients with intracerebral hemorrhage. J Neurosurg. 2013;118(1):115-20.

38. Nourian A, Mohammadi M, Beigmohammadi MT, Taher M, Dadvar Z, Malekolkottab $\mathrm{M}$, et al. Comparing efficacy of enteral nutrition plus ranitidine and enteral nutrition alone as stress ulcer prophylaxis. J Comp Eff Res. 2018:7(5):493-501.

39. Powell H, Morgan M, Li SK, Baron JH. Inhibition of gastric acid secretion in the intensive care unit after coronary artery bypass graft. A pilot control study of intravenous omeprazole by bolus and infusion, ranitidine and placebo. Theor Surg. 1993;8(3):125-30.

40. Peura DA, Johnson LF. Cimetidine for prevention and treatment of gastroduodenal mucosal lesions in patients in an intensive care unit. Ann Intern Med. 1985;103(2):173-7.

41. Reusser P, Gyr K, Scheidegger D, Buchmann B, Buser M, Zimmerli W. Prospective endoscopic study of stress erosions and ulcers in critically ill neurosurgical patients: current incidence and effect of acid-reducing prophylaxis. Crit Care Med. 1990;18(3):270-4.

42. Ruiz-Santana S, Ortiz E, Gonzalez B, Bolaños J, Ruiz-Santana AJ, Manzano JL. Stress-induced gastroduodenal lesions and total parenteral nutrition in critically ill patients: frequency, complications, and the value of prophylactic treatment. A prospective, randomized study. Crit Care Med. 1991;19(7):887-91.

43. Selvanderan SP, Summers MJ, Finnis ME, Plummer MP, Ali Abdelhamid Y, Anderson MB, et al. Pantoprazole or placebo for stress ulcer prophylaxis (POP-UP): randomized doubleblind exploratory study. Crit Care Med. 2016;44(10):1842-50.

44. Zinner MJ, Zuidema GD, Smith PL, Mignosa M. The prevention of upper gastrointestinal tract bleeding in patients in an intensive care unit. Surg Gynecol Obstet. 1981;153(2):214-20.

45. van der Voort PH. How to prevent and treat gastrointestinal bleeding in the critically ill patient: a pathophysiological approach. J Emerg Crit Care Med. 2017;1:35.

46. Plummer MP, Blaser AR, Deane AM. Stress ulceration: prevalence, pathology and association with adverse outcomes. Crit Care. 2014:18(2):213.

47. Rhodes A, Evans LE, Alhazzani W, Levy MM, Antonelli M, Ferrer R, et al. Surviving Sepsis campaign: international guidelines for Management of Sepsis and Septic Shock: 2016. Crit Care Med. 2017;45(3):486-552.

48. MacLaren R, Reynolds PM, Allen RR. Histamine-2 receptor antagonists vs proton pump inhibitors on gastrointestinal tract hemorrhage and infectious complications in the intensive care unit. JAMA Intern Med. 2014;174(4):564-74.

49. Barletta JF, Sclar DA. Proton pump inhibitors increase the risk for hospital-acquired Clostridium difficile infection in critically ill patients. Crit Care. 2014;18(6):714.
50. Kenneally C, Rosini JM, Skrupky LP, Doherty JA, Hollands JM, Martinez E, et al. Analysis of 30-day mortality for Clostridium difficile-associated disease in the ICU setting. Chest. 2007;132(2):418-24.

51. Cohen ME, Hathway JM, Salmasian H, Liu J, Terry M, Abrams JA, et al. Prophylaxis for stress ulcers with proton pump inhibitors is not associated with increased risk of bloodstream infections in the intensive care unit. Clin Gastroenterol Hepatol. 2017;15(7):1030-1036.e1.

52. Preiser JC, van Zanten AR, Berger MM, Biolo G, Casaer MP, Doig GS, et al. Metabolic and nutritional support of critically ill patients: consensus and controversies. Crit Care. 2015;19:35.

53. McClave SA, Heyland DK. The physiologic response and associated clinical benefits from provision of early enteral nutrition. Nutr Clin Pract. 2009;24(3):305-15.

54. Ephgrave KS, Kleiman-Wexler RL, Adair CG. Enteral nutrients prevent stress ulceration and increase intragastric volume. Crit Care Med. 1990;18(6):621-4.

55. Inoue S, Lukes S, Alexander JW, Trocki O, Silberstein EB. Increased gut blood flow with early enteral feeding in burned Guinea pigs. J Burn Care Rehabil. 1989;10(4):300-8.

56. Zandstra DF, Stoutenbeek CP. The virtual absence of stress-ulceration related bleeding in ICU patients receiving prolonged mechanical ventilation without any prophylaxis. A prospective cohort study. Intensive Care Med. 1994;20(5):335-40

57. Pingleton SK, Hadzima SK. Enteral alimentation and gastrointestinal bleeding in mechanically ventilated patients. Crit Care Med. 1983;11(1):13-6.

58. Bonten MJ, Gaillard CA, van Tiel FH, van der Geest S, Stobberingh EE Continuous enteral feeding counteracts preventive measures for gastric colonization in intensive care unit patients. Crit Care Med. 1994;22(6):939-44.

59. Krag M, Perner A, Wetterslev J, Wise MP, Hylander MM. Stress ulcer prophylaxis versus placebo or no prophylaxis in critically ill patients: a systematic review of randomised clinical trials with meta-analysis and trial sequential analysis. Intensive Care Med. 2014;40(1):11-22

\section{Publisher's Note}

Springer Nature remains neutral with regard to jurisdictional claims in published maps and institutional affiliations.

Ready to submit your research? Choose BMC and benefit from:

- fast, convenient online submission

- thorough peer review by experienced researchers in your field

- rapid publication on acceptance

- support for research data, including large and complex data types

- gold Open Access which fosters wider collaboration and increased citations

- maximum visibility for your research: over $100 \mathrm{M}$ website views per year

At BMC, research is always in progress.

Learn more biomedcentral.com/submissions 